\title{
Inhibitory Receptors and Checkpoints in Human NK Cells, Implications for the Immunotherapy of Cancer
}

\author{
Simona Sivori ${ }^{1+}$, Mariella Della Chiesa ${ }^{1+}$, Simona Carlomagno ${ }^{2}$, Linda Quatrini ${ }^{3}$, \\ Enrico Munari ${ }^{4}$, Paola Vacca ${ }^{3}$, Nicola Tumino ${ }^{3}$, Francesca Romana Mariotti ${ }^{3}$, \\ Maria Cristina Mingari ${ }^{1,5}$, Daniela Pende ${ }^{5 \neq}$ and Lorenzo Moretta ${ }^{3 * \neq}$
}

\begin{abstract}
1 Department of Experimental Medicine (DIMES) and Center of Excellence for Biomedical Research, University of Genoa, Genoa, Italy, ${ }^{2}$ Department of Experimental Medicine, University of Genoa, Genoa, Italy, ${ }^{3}$ Department of Immunology, IRCCS Ospedale Pediatrico Bambino Gesù, Rome, Italy, ${ }^{4}$ Department of Pathology, IRCCS Sacro Cuore Don Calabria, Negrar, Italy, ${ }^{5}$ UOC Immunology, IRCCS Ospedale Policlinico San Martino, Genoa, Italy
\end{abstract}

OPEN ACCESS

Edited by:

Renato C. Monteiro,

Université de Paris, France

Reviewed by:

Stephan von Gunten,

University of Bern, Switzerland

Ana Stojanovic,

Heidelberg University, Germany

*Correspondence:

Lorenzo Moretta

lorenzo.moretta@opbg.net

tThese authors have contributed equally to this work

FThese authors share senior authorship

Specialty section:

This article was submitted to Molecular Innate Immunity,

a section of the journal

Frontiers in Immunology

Received: 26 June 2020

Accepted: 07 August 2020 Published: 03 September 2020

Citation:

Sivori S, Della Chiesa M, Carlomagno S, Quatrini L, Munari E, Vacca P, Tumino N, Mariotti FR Mingari MC, Pende $D$ and Moretta L

(2020) Inhibitory Receptors and Checkpoints in Human NK Cells, Implications for the Immunotherapy of Cancer. Front. Immunol. 11:2156.

doi: 10.3389/fimmu.2020.02156
The highly destructive mechanisms by which the immune system faces microbial infections is under the control of a series of inhibitory receptors. While most of these receptors prevent unwanted/excessive responses of individual effector cells, others play a more general role in immunity, acting as true inhibitory checkpoints controlling both innate and adaptive immunity. Regarding human NK cells, their function is finely regulated by HLA-class I-specific inhibitory receptors which allow discrimination between $\mathrm{HLA}-\mathrm{I}^{+}$, healthy cells and tumor or virus-infected cells displaying loss or substantial alterations of HLA-I molecules, including allelic losses that are sensed by KIRs. A number of non-HLA-specific receptors have been identified which recognize cell surface or extracellular matrix ligands and may contribute to the physiologic control of immune responses and tolerance. Among these receptors, Siglec 7 (p75/AIRM-1), LAIR-1 and IRp60, recognize ligands including sialic acids, extracellular matrix/collagen or aminophospholipids, respectively. These ligands may be expressed at the surface of tumor cells, thus inhibiting NK cell function. Expression of the PD-1 checkpoint by NK cells requires particular cytokines (IL-15, IL-12, IL-18) together with cortisol, a combination that may occur in the microenvironment of different tumors. Blocking of single or combinations of inhibitory receptors unleashes NK cells and restore their anti-tumor activity, with obvious implications for tumor immunotherapy.

Keywords: natural killer cells, inhibitory NK receptors, immune checkpoints, tumor immunotherapy, tumor escape

\section{INTRODUCTION}

To combat infections, the immune system exploits highly destructive mechanisms. These mechanisms are triggered by an array of receptors that evolved during phylogenesis from structures ensuring phagocytosis and killing of invading pathogens toward highly sophisticated, clonally distributed, receptors encoded by rearranging genes. Remarkably, most of the "primitive" receptors did not disappear during evolution but rather co-evolved with adaptive immunity and are playing, in contemporary vertebrates, a synergistic role, contributing to improved anti-microbial responses. 
A good example is provided by the Fc-gamma receptors, evolved from a primitive surface protein into receptors recognizing IgG antibodies (Abs), allowing greater killing or phagocytosis of Ab-coated bacteria or target cells (1). In particular, NK cells, expressing the Fc $\gamma$ RIIIa (also known as CD16), are considered the most important effectors of antibody-dependent cell-mediated cytotoxicity (ADCC) in humans.

The exploitation of highly destructive mechanisms to control infections would require means to avoid damages to healthy cells and, in general, to the whole organism. Thus, efficient mechanisms have been acquired to prevent damages to self by downmodulating immune responses and inflammation at the termination of infection. A major role in ensuring this crucial activity is played by an array of inhibitory receptors which may control the function of individual cells of both innate and adaptive immunity and, in some instances, may function as true checkpoints, ensuring a wide control of immune response and inflammation.

Focusing on human NK cells, they express different HLA class I-specific receptors that allow discrimination between healthy and virus-infected or tumor cells (2), while other receptors such as TIGIT and CD96, although controlling NK cell function, play a role also in the regulation of cell adhesion and migration/homing (3). In this context, studies of tissue distribution of their ligands, such as PVR (CD155) and Nectin-2 (CD112), may provide useful information on the possible migration/homing of cells expressing the corresponding receptor. Other receptors, such as CD69 and CD103, represent tissue retention receptors and may provide important markers to identify NK and T cells capable of infiltrating and staying in normal peripheral tissues or tumors (4).

In this contribution, we will delineate some of the main inhibitory receptors expressed by human NK cells. Remarkably, Killer Ig-like Receptors (KIR), discovered by Moretta et al. in $1990(5,6)$ are the prototype of the inhibitory receptors controlling cells of the immune system. These and other HLA class I-specific receptors provided the molecular basis of the "missing-self hypothesis" and explained how NK cells may discriminate between healthy and tumor or virus-infected cells (7). Moreover, NK cells can express several non-HLA-specific inhibitory receptors that contribute in regulating immune responses. Some inhibitory receptors are constitutively expressed by NK cells (such as KIR and NKG2A) and are involved in the regulation of NK cell tolerance against healthy tissues, while others (such as PD-1) are expressed at very low level in NK cells from healthy donors, but increase in pathological conditions. All these inhibitory receptors act as immune checkpoints regulating anti-tumor NK cell function by the recognition of specific ligands on tumor cells thus favoring tumor escape from $\mathrm{NK}$ cell cytotoxicity.

\section{HLA-SPECIFIC INHIBITORY NK RECEPTORS}

In humans, the molecular basis for NK cell tolerance toward healthy autologous cells is provided by HLA-specific inhibitory receptors (iNKR), that are mainly represented by KIR,
CD94:NKG2A, and LILRB1 (2, 6, 8-10). Inhibitory KIRs (iKIR), characterized by 2 or 3 Ig-like extracellular domains and a long cytoplasmic tail (KIR2DL, KIR3DL), recognize allotypic determinants shared by distinct groups of HLA class I molecules (KIR-ligands, KIR-L), as recently reviewed (11). CD94:NKG2A heterodimer, composed by C-type lectin-like proteins, is specific for the non-classical HLA-E molecules, that are stabilized by peptides mainly derived from the leader sequences of HLA-A, $-B$, or $-C(12,13)$. LILRB1 displays a broad specificity for HLA $(14,15)$. Upon receptor engagement, the immunoreceptor tyrosine-based inhibitory motifs (ITIM) become phosphorylated and recruit tyrosine phosphatases, thus delivering an inhibitory signaling cascade (16-18). Table 1 and Figure $\mathbf{1}$ summarize these receptor/ligand interactions.

During NK cell development, immature stages primarily express CD94:NKG2A, while KIRs are acquired upon maturation. NK cells go through a process termed "education," involving the iNKR/self-HLA interaction, whose strength positively influences the functional potential of NK cells (19). Extremely diversified self-tolerant iNKR phenotypic repertoires can be observed on peripheral blood NK cell pool among the various individuals (17). This heterogeneity is primarily determined by the high polymorphism of the independently co-inherited KIR and HLA class I genotypes, and by the stochastic KIR expression pattern on NK cells (20). NK cells can be efficient even when expressing single-iKIR, provided that it strongly interacts with self-HLA. This NK cell can kill the pathological cell that has lost even a single-HLA allotype through the mechanism of "missing-self recognition." Regarding CD94:NKG2A/HLA-E interaction, a dimorphism in HLA-B leader sequence at residue -21 encoding either a good binding methionine $(-21 \mathrm{M})$ or a low binding threonine $(-21 \mathrm{~T})$ determines the variability in HLA-E expression; $\mathrm{NKG}_{2} \mathrm{~A}^{+}$cells from individuals carrying at least one - 21 M HLA-B alleles are more educated (21). Consistent with this finding, in acute myeloid leukemia (AML) patients treated with immunotherapy, a better leukemia-free survival (LFS) was observed in patients with $-21 \mathrm{M} / \mathrm{x}$ than $-21 \mathrm{~T} / \mathrm{T} H L A-B$ alleles (22).

In addition to genetics, environmental factors can impact on the receptor repertoire. The most remarkable example is represented by cytomegalovirus (CMV) infection, that promotes the expansion of functionally and phenotypically skewed NK cells with adaptive features through epigenetic alterations $(23,24)$. These cells are characterized by the expression of the activating CD94:NKG2C, mainly co-expressing KIR2DL specific for self-HLA-C allotypes, CD57 (a marker of terminally differentiation stage), and by the lack of NKG2A (25-27). Notably, in view of their long term persistence (28-30), expansion capabilities (31) and high ADCC abilities (32, 33), CMVdriven adaptive NK cells also represent a suitable target for anti-leukemia immunotherapeutic strategies (e.g., CD16-based immune engagers, adoptive cell transfer, CAR-engineering) (34).

KIRs have been shown to be clinically relevant in allogeneic hematopoietic stem cell transplantation (HSCT) to cure acute leukemia, in particular from HLA-haploidentical donors whose repertoire presents educated $\operatorname{iKIR}(s)$ that do not recognize the cognate KIR-L(s) in the recipient. When KIR/KIR-L mismatches 
TABLE 1 | HLA-I specific and non-HLA-I specific inhibitory receptors, their distribution and ligands.

\begin{tabular}{|c|c|c|c|c|}
\hline & Molecule & CD & Cell distribution & Ligand \\
\hline \multirow{9}{*}{$\begin{array}{l}\text { HLA specific } \\
\text { inhibitory receptors }\end{array}$} & KIR2DL1 & CD158a & NK cells, T cells & HLA-C ${ }^{K 80}$ allotypes (HLA-C2 epitope) \\
\hline & KIR2DL2/3 & CD158b1/b2 & NK cells, T cells & $\begin{array}{l}\text { HLA-C }{ }^{N 80} \text { allotypes (HLA-C1 epitope) } \\
\text { HLA-B* } 46: 01 \text { and }-B^{\star} 73: 01\end{array}$ \\
\hline & KIR2DL5 & CD158f & NK cells, T cells & $?$ \\
\hline & KIR3DL1 & CD158e1 & NK cells, T cells & HLA-A Bw4, HLA-B Bw4 \\
\hline & KIR3DL2 & CD158k & NK cells, T cells & HLA-A*03 and $-A^{*} 11, H L A-F$ \\
\hline & KIR3DL3 & CD158z & NK cells, $T$ cells & $?$ \\
\hline & LILRB1/LIR-1/ILT2 & CD85j & NK cells, T cells, B cells, monocytes, DCs & HLA-G, various HLA-I allotypes \\
\hline & NKG2A & CD159a & NK and T cells & HLA-E \\
\hline & LAG-3 & CD223 & Activated NK cells, activated T cells, B cells, pDCs & HLA-II \\
\hline \multirow{12}{*}{$\begin{array}{l}\text { Non-HLA specific } \\
\text { inhibitory receptors }\end{array}$} & PD-1 & CD279 & NK cells, T cells, B cells, myeloid cells & PD-L1, PD-L2 \\
\hline & TIM-3 & CD366 & $\begin{array}{l}\text { NK cells, T cells, DCs, monocytes, macrophages, mast } \\
\text { cells }\end{array}$ & Gal-9, PS, HMGB1, CEACAM1 \\
\hline & TIGIT & NA & NK cells, T cells & CD155, CD112, CD113 \\
\hline & Tactile & CD96 & NK cells, T cells & CD155, CD111 \\
\hline & Siglec-7/p75/AIRM-1 & CD328 & NK cells, T cells, granulocytes, monocytes, & Sialic acid \\
\hline & Siglec-9 & CD329 & NK cells, T cells, B cells, granulocytes, monocytes & Sialic acid \\
\hline & KLRG1 & NA & NK cells, T cells & cadherins \\
\hline & IRp60 & CD300a & $\begin{array}{l}\text { NK cells, T cells, B cells, neutrophils, eosinophils, mast } \\
\text { cells, pDC }\end{array}$ & $\begin{array}{l}\text { phosphatidylserine (PS), } \\
\text { phoshatidylethanolamine (PE) }\end{array}$ \\
\hline & LAIR-1/p40 & CD305 & $\begin{array}{l}\text { NK cells, T cells, B cells, monocytes, granulocytes, } \\
\text { DCs, mast cells, macrophages, CD } 34^{+} \text {hematopoietic } \\
\text { progenitor cells, thymocytes }\end{array}$ & Collagen, C1q, surfactant protein D \\
\hline & CEACAM-1 & CD66a & epithelial cells, various leukocytes & CEACAM-1, CEACAM-5 \\
\hline & NKRP1A & CD161 & NK cells, $T$ cells & LLT1 \\
\hline & IAP & CD47 & $\begin{array}{l}\text { NK cells, T cells, B cells, monocytes, macrophages, } \\
\text { DCs, neutrophils }\end{array}$ & SIRP1a, TSP-1 \\
\hline
\end{tabular}

in graft-versus-host $(\mathrm{GvH})$ direction occur, alloreactive NK cells can be generated in the transplanted patient, with efficient anti-leukemia activity (35). This has been proven especially beneficial in acute myeloid leukemia (AML) adult patients (36), and in acute lymphoblastic leukemia (ALL) pediatric patients (37). Algorithms for donor selection criteria have been created, considering NK alloreactivity and KIR gene profiles, to improve the clinical outcome in HSCT (38-41).

A great improvement in cancer immunotherapy has been achieved with immune checkpoint inhibitors (ICI), by the use of therapeutic antibodies blocking inhibitory checkpoints. With the aim to potentiate/unleash the anti-tumor NK cell function, clinical grade monoclonal antibodies (mAbs) targeting KIR and NKG2A have been produced. Lirilumab (1-7F9, IPH2101), a first-in-class fully human IgG4 mAb targeting KIR2D, has been employed in phase I trials to treat hematological malignancies or solid tumors, also in association with Lenalidomide (as NK cell stimulant) in multiple myeloma, resulting to be safe but with low anti-tumor efficacy (42-44). More promising clinical results have been obtained with IPH4102 targeting KIR3DL2 on cutaneous T cell lymphoma, particularly in Sèzary syndrome (45). Of extreme interest for the clinical potential is monalizumab, a humanized IgG4-blocking anti-NKG2A $\mathrm{mAb}$, that can unleash both $\mathrm{NK}$ and $\mathrm{T}$-cell responses (46).
Indeed, NKG2A/HLA-E interaction can downregulate antitumor immune responses. Clinical trials using monalizumab in combination with durvalumab (anti-PD-L1) for the treatment of solid tumors, and, especially, in combination with cetuximab (anti-EGFR) for the treatment of head and neck cancers, show clear signs of efficacy (46).

\section{NON-HLA-SPECIFIC INHIBITORY NK RECEPTORS}

In addition to the HLA class I-specific receptors, NK cells express several other ITIM-containing receptors importantly contributing to regulate immune responses (Table 1) (47$60)$. We focus here on the critical immune checkpoint PD-1 and on Siglec-7/p75/AIRM1/CD328, LAIR-1/p40/CD305, and IRp60/CD300a, originally identified in our labs, representing additional immune checkpoints possibly dampening anti-tumor NK cell responses in given pathological settings (Figure 1). Siglec-7, IRp60 and LAIR-1 are rarely discussed in most reviews on immune checkpoints in NK cell context, however, they represent relevant receptors to target in anti-tumor immunotherapies. Indeed, their ligands are expressed or even upregulated on several tumors. 


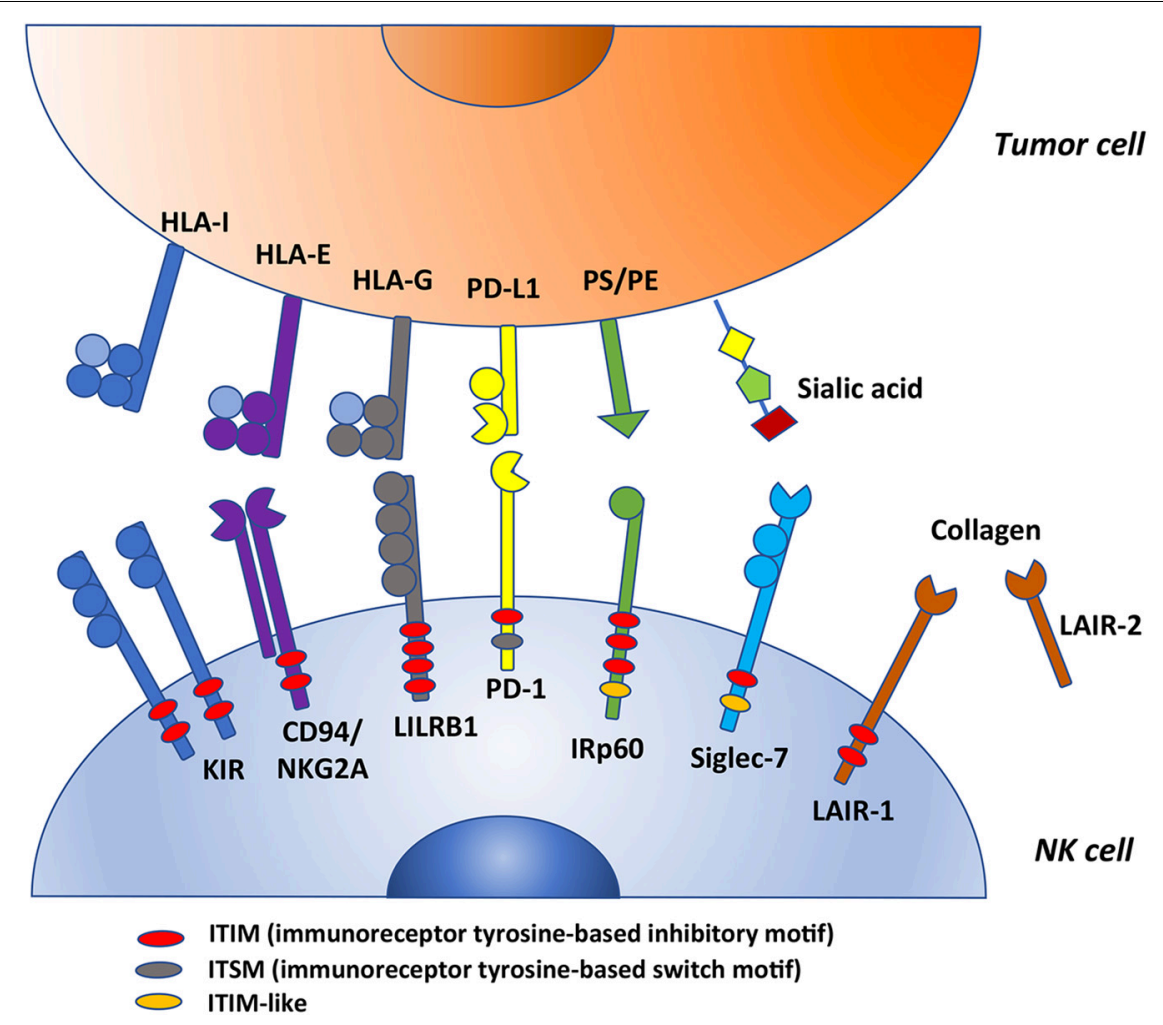

FIGURE 1 | This figure summarizes some ITIM-bearing molecules expressed by human NK cells that could act as checkpoints in cancer immunotherapy. KIRs, CD94/NKG2A and LILRB1 are HLA-specific inhibitory receptors whereas PD-1, IRp60, Siglec-7 and LAIR-1 are non-HLA-specific inhibitory receptors (their ligands are indicated in the figure). All these molecules possess variable numbers and different types of ITIMs. In particular, PD-1 express one ITIM; KIRs, CD94/NKG2A and LAIR-1 have two ITIMs (among KIRs, only KIR3DL3 and KIR2DL4 express one ITIM); IRp60 has three ITIMs; LILRB1 has four ITIMs (indicated in red in the figure). In addition, PD-1 carries also an ITSM motif (gray) whereas IRp60 and LAIR-1 an ITIM-like motif (orange). PS, phosphatidylserine; PE, phoshatidylethanolamine.

\section{PD-1}

PD-1 is a type I transmembrane glycoprotein belonging to the CD28/CTLA4 subfamily of the Ig superfamily, containing an IgV-type extracellular domain (61). Its cytoplasmic domain contains an ITIM and an immunoreceptor tyrosine-based switch motif (ITSM) and, interestingly, the tyrosine residue in the ITSM, but not in the ITIM, is required for the inhibitory cascade (62). PD-1 expression was initially described on T, B, myeloid cells and, more recently, on NK cells (47). PD-1 ligands (PD-Ls, namely PD-L1 and PD-L2) are expressed by hematopoietic and nonhematopoietic cells and, importantly, they are often expressed by tumor cells. Indeed, while in normal conditions PD-1/PD$\mathrm{L}$ axis regulates peripheral tolerance, in the context of cancer it represents a mechanism of "escape" from immune system and in particular from PD-1-expressing cytotoxic lymphocytes (63). In addition to PD-1-expressing $\mathrm{CD}^{+} \mathrm{T}$ cells, also PD$1^{+} \mathrm{NK}$ cells have been identified in several tumors, including multiple myeloma, Kaposi sarcoma, ovarian carcinoma, digestive and lung cancer $(31,47,64-66)$. Differently from $\mathrm{T}$ cells, which are induced to upregulate $\mathrm{PD}-1$ expression upon activation, NK cells from the peripheral blood of healthy donors do not express PD-1 on their surface, with the exception of a minor fraction of CMV seropositive individuals (47). Human NK cells have been shown to display an intra-cytoplasmatic pool of PD$1 \mathrm{mRNA}$ and protein localized in the Golgi (67). An analysis of pleural effusion contents from primary and metastatic tumors identified glucocorticoids as key components of the tumor microenvironment indispensable for PD-1 induction on NK cells surface, in combination with the signals from the cytokines IL-12, IL-15 and IL-18 (68). Glucocorticoids were shown to increase PD-1 expression at the transcriptional level in both human and murine NK cells $(68,69)$. In addition, in human CD56 ${ }^{\text {bright }}$ NK cells, these hormones activate a transcriptional program responsible for enhanced translation and translocation of proteins to the plasma membrane, which indirectly contributes to increase PD-1 surface expression. Notably, PD- $1^{+} \mathrm{NK}$ cells are not exhausted, but show an impaired response specifically against PD-L1-expressing target cells (68).

Blockade of the PD-1/PD-L1 axis through monoclonal antibodies represents a major breakthrough in oncology, showing significant clinical success in the treatment of several types of cancers $(70,71)$. This blockade allows unleashing not only $\mathrm{T}$ cell-, but also NK cell-mediated anti-tumor response. This is relevant especially in the treatment of tumors that have lost HLA-I expression and are thus "invisible" to T cells. Despite its success, only one third of patients is responsive to antiPD-1 immunotherapy (72). One important factor that may 
be responsible for this lack of response is represented by the misclassification of tumors in terms of PD-L1 expression. The immunohistochemical detection of this biomarker in tumor samples usually guides the decision of the appropriate therapeutic strategy, together with other parameters. PD-L1 expression heterogeneity, interclone differences among antibodies used for immunohistochemistry and inter/intra observer variability may explain why the rates of clinical response to treatment with PD-1/PD-L1 inhibitors do not always correlate with PD-L1 detected expression (73-76). Moreover, the recent identification of the molecular mechanisms driving PD-1 expression on NK cells suggests that including synthetic corticosteroids in the therapeutic regimen for cancer patients may be counterproductive in combination with the blockade of this checkpoint.

\section{SIGLEC-7/p75/AIRM1/CD328}

Siglec-7 is a surface inhibitory receptor belonging to a family of Sialic acid recognizing Immunoglobulin-like Lectins (Siglecs) that is mostly confined to NK cells, but is expressed also on monocytes, a minor fraction of $\mathrm{CD}^{+} \mathrm{T}$ cells and granulocytes $(48,77)$. Siglec-7 was originally identified as a 75 $\mathrm{kD}$ glycoprotein, encoded by a gene located on chromosome 19 where most inhibitory receptors regulating NK-mediated cytotoxicity are found (i.e., KIRs, LILRB1, and LAIR-1) (48). In line with most inhibitory receptors, Siglec-7 is characterized by Ig-like domains in the extracellular portion and a classical ITIM, together with an ITIM-like domain, in its cytoplasmic tail, capable of switching off activating signals on NK cells (48). Siglec-7 preferentially binds to $\alpha 2-6$-linked sialic acids and to $\alpha 2,8$-disialic acid that is found on GD3 ganglioside (78).

Siglec-7, along with other Siglecs, can regulate immune responses contributing to immune tolerance, however, it can also decrease anti-tumor immunity on account of the aberrant expression of sialylated glycans on the surface of malignant cells of different histotypes [e.g., AML, CLL, melanoma, renal cell carcinoma, colon adenocarcinoma $(79,80)]$. Indeed, hypersialylation represents a relevant tumor escape mechanism that can directly affect NK cell-mediated tumor killing, as demonstrated by reduced NK cell-cytotoxicity against tumors expressing Siglec-7 ligands. Remarkably, the employ of antibodies blocking Siglec-7 engagement could restore tumor lysis (80-82). Interestingly, Siglec-7 reduced expression represents a hallmark of CMV-driven adaptive NK cell subsets $(32,33)$ and could favor their cytotoxicity against HLA-I ${ }^{\text {low/neg }}$ tumors.

Based on the above observations, Siglec-7 represents an attractive immune checkpoint that can be targeted to enhance anti-tumor responses (83). In this context, besides anti-Siglec7 blocking antibodies, different approaches have been proposed, including the employ of small soluble Siglec-7 ligands, designed to display high avidity for the receptor based on its crystal structure $(84,85)$. These molecules can increase NK-cell mediated tumor lysis although less efficiently than specific antiSiglec-7 antibodies (86). Interestingly, a recent study showed that cells engineered with a Siglec-7-based CAR construct can display efficient anti-tumor activity both in vitro against several tumor cell lines expressing Siglec-7 ligands and in vivo in xenograft murine models (87).

\section{LAIR-1/p40/CD305}

Another non-HLA-specific inhibitory NK receptor is represented by the Leukocyte-Associated Immunoglobulin-like Receptor-1 (LAIR-1) $(88,89)$, which is a type I transmembrane glycoprotein characterized by an extracellular C2-type Ig-like domain and two ITIMs in the cytoplasmic tail $(90,91)$.

LAIR-1 is one of the most widely distributed inhibitory receptors and could play a role in controlling various phases of the immune response. Indeed, it is expressed not only on NK cells but also on other cells of innate immunity (such as monocytes, granulocytes, dendritic cells, mast cells, macrophages) (90, 92-94), on T and B lymphocytes (49, 95, 96), on $\mathrm{CD}_{3}{ }^{+}$hematopoietic progenitor cells (97) and on the majority of thymocytes (90). Interestingly, during the process of cell maturation and activation LAIR-1 expression is decreased on various immune cells (i.e., CD4 ${ }^{+}$T cells, neutrophils, B cells) (93, 96, 98).

The interaction between LAIR-1 and its several ligands, such as extracellular matrix collagens (99), the C1q complement component (100), and the surfactant protein D (101), induces phosphorylation of both ITIMs and inhibition of the immune cell activation or differentiation. In particular, the LAIR-1 cross-linking with monoclonal antibodies, or with its ligands, inhibits the NK and CTL cytotoxicity (102). LAIR-1-mediated inhibition occurs through SHP-1 and SHP-2, but also through the recruitment of Csk (103) that inactivates Src family kinases.

Remarkably, the upregulation of collagen expression by tumor cells and/or tumor stroma could lead to the downregulation of anti-tumor responses mediated by the inhibitory collagen receptor LAIR-1 expressed on NK cells and other effector immune cells.

LAIR-1 can be also detected in the supernatant of stimulated human lymphocytes, suggesting its shedding upon cellular activation (104). In the soluble form, LAIR-1 could interfere with the interaction between the transmembrane receptor and its ligands, thus restoring functions of immune cells.

A similar result could also occur with the LAIR-2 protein that is $84 \%$ homologous to LAIR-1 but lacks the transmembrane and intracellular domain. Indeed, the binding of LAIR-2 to collagens could efficiently block LAIR-1-collagen interaction (105). On this basis, an interesting approach has been developed to block immune suppression mediated by LAIR-1. It is based on the use of NC410, a novel reagent capable of mimicking the natural decoy effects of LAIR-2. The blockade of the LAIR-1-mediated inhibition by NC410 can restore the normal functionality of T and dendritic cells as well as the anti-tumor response ${ }^{1}$. In this context, it could be interesting to evaluate whether the increment of anti-tumor response mediated by NC410 can depend also on restoring of the NK cell function.

\footnotetext{
${ }^{1}$ www.nextcure.com/pipeline
} 


\section{IRp60/CD300a}

IRp60/CD300a is an inhibitory receptor belonging to CD300 family, a set of genes clustered on chromosome 17 coding for receptors, predominantly expressed on leukocytes, able to generate inhibitory and activating signals regulating different immune processes, such as phagocytosis, cytokine release, proliferation and diseases $(80,106-112)$. In addition to NK cells, IRp60 is broadly expressed in cells of myeloid or lymphoid origin such as neutrophils (113), eosinophils (106), mast cells (114), pDC (113), B and T cells (115). IRp60 is expressed by the majority of blood NK cells but at higher level in CD56 ${ }^{\text {bright }}$ subset (50). Curiously it has been observed an age-dependent increase of IRp60 expression on NK cells that, in CMV seropositive donors, is associated with increase of CD56 ${ }^{\mathrm{dim}} \mathrm{NK}$ cells co-expressing CD57 (116).

IRp60 is a type I transmembrane protein with a single extracellular Ig V-like domain and a long cytoplasmic tail with three canonical ITIMs whose phosphorylation is required for the transmission of the inhibitory signal $(50,117)$. This inhibitory signal is able to strongly reduce NK cell cytotoxicity induced via different non-HLA-specific or HLA-specific activating receptors (50). IRp60 recognizes phosphatidylserine (PS) and phosphatidylethanolamine (PE), two aminophospholipids exposed on plasma membrane of activated, infected, transformed or apoptotic cells $(107,118-121)$. Expression of PS on tumor cells has been demonstrated to protect different tumor cell lines from NK cell mediated cytotoxicity (119). Moreover, IRp60 also binds non-lipid molecules such as the human adenovirus-D47 E3/49K protein (122).

To date, a clear role in the control of NK functions in hematological or solid tumors has not been described. However, IRp60 mRNA is highly expressed and associated with poor prognosis in AML (123) and in diffuse large B-cell lymphoma (124), it is hypoxia-inducible in primary human monocytes and macrophages (125) and is up-regulated in tumor-associated macrophages in ovarian carcinoma (126).

\section{CONCLUDING REMARKS}

The groundbreaking discoveries of an array of inhibitory receptors controlling the function of individual cells or even of

\section{REFERENCES}

1. Janeway CA Jr. Approaching the asymptote? Evolution and revolution in immunology. Cold Spring Harb Symp Quant Biol. (1989) 54(Pt 1):1-13. doi: 10.1101/sqb.1989.054.01.003

2. Moretta A, Bottino C, Vitale M, Pende D, Biassoni R, Mingari MC, et al. Receptors for HLA class-I molecules in human natural killer cells. Annu Rev Immunol. (1996) 14:619-48. doi: 10.1146/annurev.immunol.14. 1.619

3. Castriconi R, Carrega P, Dondero A, Bellora F, Casu B, Regis S, et al. Molecular mechanisms directing migration and retention of natural killer cells in human tissues. Front Immunol. (2018) 9:2324. doi: 10.3389/fimmu. 2018.02324 the entire immune response provided tools for unprecedented progress in the therapy of cancer. Thus, KIRs recognizing allotypic determinants on cells offered the means to successfully treat patients with high-risk leukemias by the haplo-HSCT, mostly exploiting alloreactivity of donor-derived NK cells. Perhaps more importantly, the use of checkpoint inhibitors revolutioned the clinical outcome of different lethal-cancers, by reactivating "dormant" effectors potentially capable of destroying tumor cells. Other important receptors controlling cell adhesion/migration, tissue retention or blocking effector cell function at the tumor site, are being investigated in preclinical and clinical settings. It is conceivable that a deeper knowledge of inhibitory receptors useful in the control of excessive immune responses or inflammation, but playing a detrimental role in tumors, will offer important clues for identifying the prevalent mechanism of immunosuppression in a given tumor and to apply specific, evidence-based, approaches for cancer immunotherapy. This is particularly relevant if we consider that some inhibitory receptors are characterized by a broad expression, non-restricted only to NK cells. Thus, immunotherapeutic approaches blocking these inhibitory pathways could act on different types of immune cells, allowing to re-establish a correct cross-talk between the cells of the immune system, an event which is the basis of an optimal antitumor response.

\section{AUTHOR CONTRIBUTIONS}

All authors have provided intellectual contribution to the work and approved it for publication.

\section{FUNDING}

Supported by the following grants: AIRC $5 \times 10002018$ id. 21147 (LM and SS); AIRC IG 2017 id. 19920 (LM); AIRC IG 2017 id. 20312 (SS); AIRC IG 2015 id. 16764 (DP); PRIN 2017WC8499_004 (SS); H2020-MSCA-ITN-2017-765104"MATURE-NK" (DP); RC-2019 IRCCS Ospedale Policlinico San Martino (DP); RC-2020 OPBG (LM). AIRC and European Union's Horizon 2020 Research and Innovation Program under the Marie Skłodowska-Curie grant agreement No 800924 (LQ); AIRC fellowship (NT); Fondazione Veronesi fellowship (FM).

4. Freud AG, Mundy-Bosse BL, Yu J, Caligiuri MA. The broad spectrum of human natural killer cell diversity. Immunity. (2017) 47:820-33. doi: 10.1016/ j.immuni.2017.10.008

5. Moretta A, Tambussi G, Bottino C, Tripodi G, Merli A, Ciccone E, et al. A novel surface antigen expressed by a subset of human CD3-CD16+ natural killer cells. Role in cell activation and regulation of cytolytic function. J Exp Med. (1990) 171:695-714. doi: 10.1084/jem.171.3.695

6. Moretta A, Vitale M, Bottino C, Orengo AM, Morelli L, Augugliaro R, et al. P58 molecules as putative receptors for major histocompatibility complex (MHC) class I molecules in human natural killer (NK) cells. Anti-p58 antibodies reconstitute lysis of MHC class I-protected cells in NK clones displaying different specificities. J Exp Med. (1993) 178:597-604. doi: 10. 1084/jem.178.2.597 
7. Ljunggren HG, Karre K. In search of the 'missing self': MHC molecules and NK cell recognition. Immunol Today. (1990) 11:237-44. doi: 10.1016/01675699(90)90097-s

8. Moretta A, Vitale M, Sivori S, Bottino C, Morelli L, Augugliaro R, et al. Human natural killer cell receptors for HLA-class I molecules. Evidence that the Kp43 (CD94) molecule functions as receptor for HLA-B alleles. J Exp Med. (1994) 180:545-55. doi: 10.1084/jem.180.2.545

9. Colonna M. Specificity and function of immunoglobulin superfamily NK cell inhibitory and stimulatory receptors. Immunol Rev. (1997) 155:127-33. doi: 10.1111/j.1600-065x.1997.tb00945.x

10. Lanier LL. NK cell receptors. Ann Rev Immunol. (1998) 16:359-93. doi: 10.1146/annurev.immunol.16.1.359

11. Pende D, Falco M, Vitale M, Cantoni C, Vitale C, Munari E, et al. Killer Iglike receptors (KIRs): their role in NK cell modulation and developments leading to their clinical exploitation. Front Immunol. (2019) 10:1179. doi: 10.3389/fimmu.2019.01179

12. Lee N, Llano M, Carretero M, Ishitani A, Navarro F, Lopez-Botet M, et al. HLA-E is a major ligand for the natural killer inhibitory receptor CD94/NKG2A. Proc Natl Acad Sci USA. (1998) 95:5199-204. doi: 10.1073/ pnas.95.9.5199

13. Braud VM, Allan DS, O'Callaghan CA, Soderstrom K, D'Andrea A, Ogg GS, et al. HLA-E binds to natural killer cell receptors CD94/NKG2A, B and C. Nature. (1998) 391:795-9. doi: 10.1038/35869

14. Colonna M, Navarro F, Bellon T, Llano M, Garcia P, Samaridis J, et al. A common inhibitory receptor for major histocompatibility complex class I molecules on human lymphoid and myelomonocytic cells. J Exp Med. (1997) 186:1809-18. doi: 10.1084/jem.186.11.1809

15. Shiroishi M, Tsumoto K, Amano K, Shirakihara Y, Colonna M, Braud VM, et al. Human inhibitory receptors Ig-like transcript 2 (ILT2) and ILT4 compete with CD8 for MHC class I binding and bind preferentially to HLA-G. Proc Natl Acad Sci USA. (2003) 100:8856-61. doi: 10.1073/pnas. 1431057100

16. Marsh SG, Parham P, Dupont B, Geraghty DE, Trowsdale J, Middleton $D$, et al. Killer-cell immunoglobulin-like receptor (KIR) nomenclature report, 2002. Hum Immunol. (2003) 64:648-54. doi: 10.1016/s0198-8859(03) 00067-3

17. Parham P. MHC class I molecules and KIRs in human history, health and survival. Nat Rev Immunol. (2005) 5:201-14. doi: 10.1038/nri1570

18. Long EO. Negative signaling by inhibitory receptors: the NK cell paradigm. Immunol Rev. (2008) 224:70-84. doi: 10.1111/j.1600-065X.2008.00660.x

19. Elliott JM, Yokoyama WM. Unifying concepts of MHC-dependent natural killer cell education. Trends Immunol. (2011) 32:364-72. doi: 10.1016/j.it. 2011.06.001

20. Boudreau JE, Hsu KC. Natural killer cell education and the response to infection and cancer therapy: stay tuned. Trends Immunol. (2018) 39:222-39. doi: 10.1016/j.it.2017.12.001

21. Horowitz A, Djaoud Z, Nemat-Gorgani N, Blokhuis J, Hilton HG, Beziat $\mathrm{V}$, et al. Class I HLA haplotypes form two schools that educate NK cells in different ways. Sci Immunol. (2016) 1:eaag1672. doi: 10.1126/sciimmunol. aag1672 .

22. Hallner A, Bernson E, Hussein BA, Ewald Sander F, Brune M, Aurelius J, et al. The HLA-B -21 dimorphism impacts on NK cell education and clinical outcome of immunotherapy in acute myeloid leukemia. Blood. (2019) 133:1479-88. doi: 10.1182/blood-2018-09-874990

23. Sun JC, Lopez-Verges S, Kim CC, DeRisi JL, Lanier LLNK. cells and immune "memory". J Immunol. (2011) 186:1891-7. doi: 186/4/1891 [pii]10.4049/jimmunol.1003035.

24. Rolle A, Brodin P. Immune adaptation to environmental influence: the case of NK Cells and HCMV. Trends Immunol. (2016) 37:233-43. doi: 10.1016/j. it.2016.01.005

25. Guma M, Angulo A, Vilches C, Gomez-Lozano N, Malats N, Lopez-Botet M. Imprint of human cytomegalovirus infection on the NK cell receptor repertoire. Blood. (2004) 104:3664-71. doi: 10.1182/blood-2004-05-2058 2004-05-2058 [pii].

26. Schlums H, Cichocki F, Tesi B, Theorell J, Beziat V, Holmes TD, et al. Cytomegalovirus infection drives adaptive epigenetic diversification of NK cells with altered signaling and effector function. Immunity. (2015) 42:44356. doi: $10.1016 /$ j.immuni.2015.02.008
27. Lee J, Zhang T, Hwang I, Kim A, Nitschke L, Kim M, et al. Epigenetic modification and antibody-dependent expansion of memory-like NK cells in human cytomegalovirus-infected individuals. Immunity. (2015) 42:431-42. doi: 10.1016/j.immuni.2015.02.013

28. Foley B, Cooley S, Verneris MR, Pitt M, Curtsinger J, Luo X, et al. Cytomegalovirus reactivation after allogeneic transplantation promotes a lasting increase in educated $\mathrm{NKG} 2 \mathrm{C}+$ natural killer cells with potent function. Blood. (2011) 119:2665-74. doi: 10.1182/blood-2011-10-386995

29. Della Chiesa M, Falco M, Podesta M, Locatelli F, Moretta L, Frassoni F, et al. Phenotypic and functional heterogeneity of human NK cells developing after umbilical cord blood transplantation: a role for human cytomegalovirus? Blood. (2012) 119:399-410. doi: 10.1182/blood-2011-08-372003

30. Muccio L, Falco M, Bertaina A, Locatelli F, Frassoni F, Sivori S, et al. Late development of fcepsilonrgamma(neg) adaptive natural killer cells upon human cytomegalovirus reactivation in umbilical cord blood transplantation recipients. Front Immunol. (2018) 9:1050. doi: 10.3389/fimmu.2018.01050

31. Liu Y, Cheng Y, Xu Y, Wang Z, Du X, Li C, et al. Increased expression of programmed cell death protein 1 on NK cells inhibits NK-cell-mediated antitumor function and indicates poor prognosis in digestive cancers. Oncogene. (2017) 36:6143-53. doi: 10.1038/onc.2017.209

32. Cichocki F, Cooley S, Davis Z, DeFor TE, Schlums H, Zhang B, et al. CD56dimCD57+NKG2C+ NK cell expansion is associated with reduced leukemia relapse after reduced intensity HCT. Leukemia. (2016) 30:456-63. doi: 10.1038/leu.2015.260

33. Muccio L, Bertaina A, Falco M, Pende D, Meazza R, Lopez-Botet M, et al. Analysis of memory-like natural killer cells in human cytomegalovirusinfected children undergoing alphabeta $\mathrm{T}$ and $\mathrm{B}$ cell-depleted hematopoietic stem cell transplantation for hematological malignancies. Haematologica. (2016) 101:371-81. doi: 10.3324/haematol.2015.134155

34. Sivori S, Meazza R, Quintarelli C, Carlomagno S, Della Chiesa M, Falco M, et al. NK cell-based immunotherapy for hematological malignancies. J Clin Med. (2019) 8:1702. doi: 10.3390/jcm8101702

35. Locatelli F, Pende D, Falco M, Della Chiesa M, Moretta A, Moretta L. NK cells mediate a crucial graft-versus-leukemia effect in haploidentical-HSCT to cure high-risk acute leukemia. Trends Immunol. (2018) 39:577-90. doi: 10.1016/j.it.2018.04.009

36. Ruggeri L, Capanni M, Urbani E, Perruccio K, Shlomchik WD, Tosti A, et al. Effectiveness of donor natural killer cell alloreactivity in mismatched hematopoietic transplants. Science. (2002) 295:2097-100. doi: 10.1126/ science. 1068440

37. Pende D, Marcenaro S, Falco M, Martini S, Bernardo ME, Montagna D, et al. Anti-leukemia activity of alloreactive NK cells in KIR ligand-mismatched haploidentical HSCT for pediatric patients: evaluation of the functional role of activating KIR and redefinition of inhibitory KIR specificity. Blood. (2009) 113:3119-29. doi: 10.1182/blood-2008-06-164103

38. Cooley S, Weisdorf DJ, Guethlein LA, Klein JP, Wang T, Le CT, et al. Donor selection for natural killer cell receptor genes leads to superior survival after unrelated transplantation for acute myelogenous leukemia. Blood. (2010) 116:2411-9. doi: 10.1182/blood-2010-05-283051

39. Locatelli F, Merli P, Pagliara D, Li Pira G, Falco M, Pende D, et al. Outcome of children with acute leukemia given HLA-haploidentical HSCT after alphabeta T-cell and B-cell depletion. Blood. (2017) 130:677-85. doi: 10.1182/ blood-2017-04-779769

40. Babor F, Peters C, Manser AR, Glogova E, Sauer M, Pötschger U, et al. Presence of centromeric but absence of telomeric group B KIR haplotypes in stem cell donors improve leukaemia control after HSCT for childhood ALL. Bone Marrow Transplant. (2019) 54:1847-58. doi: 10.1038/s41409-0190543-z

41. Weisdorf D, Cooley S, Wang T, Trachtenberg E, Vierra-Green C, Spellman S, et al. KIR B donors improve the outcome for AML patients given reduced intensity conditioning and unrelated donor transplantation. Blood Adv. (2020) 4:740-54. doi: 10.1182/bloodadvances.2019001053

42. Benson DM Jr., Cohen AD, Jagannath S, Munshi NC, Spitzer G, Hofmeister CC, et al. A phase I trial of the anti-KIR antibody IPH2101 and lenalidomide in patients with relapsed/refractory multiple myeloma. Clin Cancer Res. (2015) 21:4055-61. doi: 10.1158/1078-0432.CCR-15-0304

43. Carlsten M, Korde N, Kotecha R, Reger R, Bor S, Kazandjian D, et al. Checkpoint inhibition of KIR2D with the monoclonal antibody IPH2101 
induces contraction and hyporesponsiveness of NK cells in patients with myeloma. Clin Cancer Res. (2016) 22:5211-22. doi: 10.1158/1078-0432.CCR16-1108

44. Vey N, Karlin L, Sadot-Lebouvier S, Broussais F, Berton-Rigaud D, Rey J, et al. A phase 1 study of lirilumab (antibody against killer immunoglobulinlike receptor antibody KIR2D; IPH2102) in patients with solid tumors and hematologic malignancies. Oncotarget. (2018) 9:17675-88. doi: 10.18632/ oncotarget.24832

45. Bagot M, Porcu P, Marie-Cardine A, Battistella M, William BM, Vermeer $\mathrm{M}$, et al. IPH4102, a first-in-class anti-KIR3DL2 monoclonal antibody, in patients with relapsed or refractory cutaneous T-cell lymphoma: an international, first-in-human, open-label, phase 1 trial. Lancet Oncol. (2019) 20:1160-70. doi: 10.1016/S1470-2045(19)30320-1

46. Andre P, Denis C, Soulas C, Bourbon-Caillet C, Lopez J, Arnoux T, et al. AntiNKG2A mAb is a checkpoint inhibitor that promotes anti-tumor immunity by unleashing both T and NK cells. Cell. (2018) 175:1731-43.e13. doi: 10 . 1016/j.cell.2018.10.014

47. Pesce S, Greppi M, Tabellini G, Rampinelli F, Parolini S, Olive D, et al. Identification of a subset of human natural killer cells expressing high levels of programmed death 1: a phenotypic and functional characterization. $J$ Allergy Clin Immunol. (2017) 139:335-46.e3. doi: 10.1016/j.jaci.2016.04.025

48. Falco M, Biassoni R, Bottino C, Vitale M, Sivori S, Augugliaro R, et al. Identification and molecular cloning of p75/AIRM1, a novel member of the sialoadhesin family that functions as an inhibitory receptor in human natural killer cells. J Exp Med. (1999) 190:793-802. doi: 10.1084/jem.190.6.793

49. Poggi A, Tomasello E, Revello V, Nanni L, Costa P, Moretta L. p40 molecule regulates NK cell activation mediated by NK receptors for HLA class I antigens and TCR-mediated triggering of $\mathrm{T}$ lymphocytes. Int Immunol. (1997) 9:1271-9. doi: 10.1093/intimm/9.9.1271

50. Cantoni C, Bottino C, Augugliaro R, Morelli L, Marcenaro E, Castriconi $\mathrm{R}$, et al. Molecular and functional characterization of IRp60, a member of the immunoglobulin superfamily that functions as an inhibitory receptor in human NK cells. Eur J Immunol. (1999) 29:3148-59. doi: 10.1002/(SICI) 1521-4141(199910)29:103.0.CO;2-L

51. Triebel F, Jitsukawa S, Baixeras E, Roman-Roman S, Genevee C, ViegasPequignot E, et al. LAG-3, a novel lymphocyte activation gene closely related to CD4. J Exp Med. (1990) 171:1393-405. doi: 10.1084/jem.171.5.1393

52. Ndhlovu LC, Lopez-Verges S, Barbour JD, Jones RB, Jha AR, Long BR, et al. Tim-3 marks human natural killer cell maturation and suppresses cellmediated cytotoxicity. Blood. (2012) 119:3734-43. doi: 10.1182/blood-201111-392951

53. Stanietsky N, Simic H, Arapovic J, Toporik A, Levy O, Novik A, et al. The interaction of TIGIT with PVR and PVRL2 inhibits human NK cell cytotoxicity. Proc Natl Acad Sci USA. (2009) 106:17858-63. doi: 10.1073/ pnas. 0903474106

54. Fuchs A, Cella M, Giurisato E, Shaw AS, Colonna M. Cutting edge: CD96 (tactile) promotes NK cell-target cell adhesion by interacting with the poliovirus receptor (CD155). J Immunol. (2004) 172:3994-8. doi: 10.4049/ jimmunol.172.7.3994

55. Zhang JQ, Nicoll G, Jones C, Crocker PR. Siglec-9, a novel sialic acid binding member of the immunoglobulin superfamily expressed broadly on human blood leukocytes. J Biol Chem. (2000) 275:22121-6. doi: 10.1074/jbc. M002788200

56. Lopez-Verges S, Milush JM, Pandey S, York VA, Arakawa-Hoyt J, Pircher $\mathrm{H}$, et al. CD57 defines a functionally distinct population of mature NK cells in the human CD56dimCD16+ NK-cell subset. Blood. (2010) 116:3865-74. doi: 10.1182/blood-2010-04-282301

57. Markel G, Lieberman N, Katz G, Arnon TI, Lotem M, Drize O, et al. CD66a interactions between human melanoma and NK cells: a novel class I MHC-independent inhibitory mechanism of cytotoxicity. J Immunol. (2002) 168:2803-10. doi: 10.4049/jimmunol.168.6.2803

58. Aldemir H, Prod'homme V, Dumaurier MJ, Retiere C, Poupon G, Cazareth J, et al. Cutting edge: lectin-like transcript 1 is a ligand for the CD161 receptor. J Immunol. (2005) 175:7791-5. doi: 10.4049/jimmunol.175.12.7791

59. Nath PR, Pal-Nath D, Mandal A, Cam MC, Schwartz AL, Roberts DD. Natural killer cell recruitment and activation are regulated by $\mathrm{CD} 47$ expression in the tumor microenvironment. Cancer Immunol Res. (2019) 7:1547-61. doi: 10.1158/2326-6066.CIR-18-0367
60. Khan M, Arooj S, Wang HNK. Cell-based immune checkpoint inhibition. Front Immunol. (2020) 11:167. doi: 10.3389/fimmu.2020.00167

61. Chamoto K, Al-Habsi M, Honjo T. Role of PD-1 in immunity and diseases. Curr Top Microbiol Immunol. (2017) 410:75-97. doi: 10.1007/82_2017_67

62. Okazaki T, Maeda A, Nishimura H, Kurosaki T, Honjo TPD-. 1 immunoreceptor inhibits B cell receptor-mediated signaling by recruiting src homology 2-domain-containing tyrosine phosphatase 2 to phosphotyrosine. Proc Natl Acad Sci USA. (2001) 98:13866-71. doi: 10.1073/pnas.231486598

63. Mariotti FR, Quatrini L, Munari E, Vacca P, Moretta L. Innate lymphoid cells: expression of PD-1 and other checkpoints in normal and pathological conditions. Front Immunol. (2019) 10:910. doi: 10.3389/fimmu.2019.00910

64. Benson DM Jr., Bakan CE, Mishra A, Hofmeister CC, Efebera Y, Becknell B, et al. The PD-1/PD-L1 axis modulates the natural killer cell versus multiple myeloma effect: a therapeutic target for CT-011, a novel monoclonal antiPD-1 antibody. Blood. (2010) 116:2286-94. doi: 10.1182/blood-2010-02271874

65. Beldi-Ferchiou A, Lambert M, Dogniaux S, Vely F, Vivier E, Olive D, et al. PD-1 mediates functional exhaustion of activated NK cells in patients with Kaposi sarcoma. Oncotarget. (2016) 7:72961-77. doi: 10.18632/oncotarget. 12150

66. Tumino N, Martini S, Munari E, Scordamaglia F, Besi F, Mariotti FR, et al. Presence of innate lymphoid cells in pleural effusions of primary and metastatic tumors: functional analysis and expression of PD-1 receptor. Int $J$ Cancer. (2019) 145:1660-8. doi: 10.1002/ijc.32262

67. Mariotti FR, Petrini S, Ingegnere T, Tumino N, Besi F, Scordamaglia F, et al. PD-1 in human NK cells: evidence of cytoplasmic mRNA and protein expression. Oncoimmunology. (2019) 8:1557030. doi: 10.1080/2162402X. 2018.1557030

68. Quatrini L, Vacca P, Tumino N, Besi F, Di Pace AL, Scordamaglia F, et al. Glucocorticoids and the cytokines IL-12, IL-15 and IL-18 present in the tumor microenvironment induce PD-1 expression on human Natural Killer cells. J Allergy Clin Immunol. (2020). (in press). doi: 10.1016/j.jaci.2020.04. 044

69. Quatrini L, Wieduwild E, Escaliere B, Filtjens J, Chasson L, Laprie C, et al. Endogenous glucocorticoids control host resistance to viral infection through the tissue-specific regulation of PD-1 expression on NK cells. Nat Immunol. (2018) 19:954-62. doi: 10.1038/s41590-0180185-0

70. Mariotti FR, Quatrini L, Munari E, Vacca P, Tumino N, Pietra G, et al. Inhibitory checkpoints in human natural killer cells: IUPHAR Review 28. $\mathrm{Br}$ J Pharmacol. (2020) 177:2889-903. doi: 10.1111/bph.15081

71. Pardoll DM. The blockade of immune checkpoints in cancer immunotherapy. Nat Rev Cancer. (2012) 12:252-64. doi: 10.1038/nrc3239

72. Sholl LM, Aisner DL, Allen TC, Beasley MB, Borczuk AC, Cagle PT, et al. Programmed death ligand-1 immunohistochemistry-a new challenge for pathologists: a perspective from members of the pulmonary pathology society. Arch Pathol Lab Med. (2016) 140:341-4. doi: 10.5858/arpa.20150506-SA

73. Munari E, Zamboni G, Marconi M, Sommaggio M, Brunelli M, Martignoni $\mathrm{G}$, et al. PD-L1 expression heterogeneity in non-small cell lung cancer: evaluation of small biopsies reliability. Oncotarget. (2017) 8:90123-31. doi: 10.18632/oncotarget.21485

74. Munari E, Zamboni G, Lunardi G, Marchionni L, Marconi M, Sommaggio $\mathrm{M}$, et al. PD-L1 expression heterogeneity in non-small cell lung cancer: defining criteria for harmonization between biopsy specimens and whole sections. J Thorac Oncol. (2018) 13:1113-20. doi: 10.1016/j.jtho.2018. 04.017

75. Munari E, Rossi G, Zamboni G, Lunardi G, Marconi M, Sommaggio M, et al. PD-L1 Assays 22C 3 and SP263 are Not interchangeable in non-small cell lung cancer when considering clinically relevant cutoffs: an interclone evaluation by differently trained pathologists. Am J Surg Pathol. (2018) 42:1384-9. doi: 10.1097/PAS.0000000000001105

76. Munari E, Zamboni G, Lunardi G, Marconi M, Sommaggio M, Brunelli M, et al. PD-L1 expression comparison between primary and relapsed non-small cell lung carcinoma using whole sections and clone SP263. Oncotarget. (2018) 9:30465-71. doi: 10.18632/oncotarget.25770

77. Nicoll G, Ni J, Liu D, Klenerman P, Munday J, Dubock S, et al. Identification and characterization of a novel siglec, siglec-7, expressed by human natural 
killer cells and monocytes. J Biol Chem. (1999) 274:34089-95. doi: 10.1074/ jbc.274.48.34089

78. Yamaji T, Teranishi T, Alphey MS, Crocker PR, Hashimoto YA. small region of the natural killer cell receptor, Siglec-7, is responsible for its preferred binding to alpha 2,8-disialyl and branched alpha 2,6-sialyl residues. A comparison with Siglec-9. J Biol Chem. (2002) 277:6324-32. doi: 10.1074/ jbc.M110146200

79. Santegoets KCM, Gielen PR, Bull C, Schulte BM, Kers-Rebel, Kusters B, et al. Expression profiling of immune inhibitory Siglecs and their ligands in patients with glioma. Cancer Immunol Immunother. (2019) 68:937-49. doi: 10.1007/s00262-019-02332-w

80. Jandus C, Boligan KF, Chijioke O, Liu H, Dahlhaus M, Demoulins T, et al. Interactions between Siglec-7/9 receptors and ligands influence NK celldependent tumor immunosurveillance. J Clin Investigat. (2014) 124:1810-20. doi: 10.1172/JCI65899

81. Kawasaki Y, Ito A, Withers DA, Taima T, Kakoi N, Saito S, et al. Ganglioside DSGb5, preferred ligand for Siglec-7, inhibits NK cell cytotoxicity against renal cell carcinoma cells. Glycobiology. (2010) 20:1373-9. doi: 10.1093/ glycob/cwq116

82. Nicoll G, Avril T, Lock K, Furukawa K, Bovin N, Crocker PR. Ganglioside GD3 expression on target cells can modulate NK cell cytotoxicity via siglec-7dependent and -independent mechanisms. Eur J Immunol. (2003) 33:1642-8. doi: $10.1002 /$ eji.200323693

83. Daly J, Carlsten M, O’Dwyer M. Sugar free: novel immunotherapeutic approaches targeting siglecs and sialic acids to enhance natural killer cell cytotoxicity against cancer. Front Immunol. (2019) 10:1047. doi: 10.3389/ fimmu.2019.01047

84. Alphey MS, Attrill H, Crocker PR, van Aalten DM. High resolution crystal structures of Siglec-7. Insights into ligand specificity in the Siglec family. $J$ Biolo Chem. (2003) 278:3372-7. doi: 10.1074/jbc.M210602200

85. Dimasi N, Moretta A, Moretta L, Biassoni R, Mariuzza RA. Structure of the saccharide-binding domain of the human natural killer cell inhibitory receptor p75/AIRM1. Acta Crystallogr Sect D Biol Crystallogr. (2004) 60(Pt 2):401-3. doi: $10.1107 / \$ 0907444903028439$

86. Prescher H, Frank M, Gutgemann S, Kuhfeldt E, Schweizer A, Nitschke L, et al. Design, synthesis, and biological evaluation of small, high-affinity siglec7 ligands: toward novel inhibitors of cancer immune evasion. J Med Chem. (2017) 60:941-56. doi: 10.1021/acs.jmedchem.6b01111

87. Meril S, Harush O, Reboh Y, Matikhina T, Barliya T, Cohen CJ. Targeting glycosylated antigens on cancer cells using siglec-7/9-based CAR T-cells. Mol Carcinogenes. (2020) 59:713-23. doi: 10.1002/mc.23213

88. Poggi A, Pella N, Morelli L, Spada F, Revello V, Sivori S, et al. p40, a novel surface molecule involved in the regulation of the non-major histocompatibility complex-restricted cytolytic activity in humans. Eur $J$ Immunol. (1995) 25:369-76. doi: 10.1002/eji.1830250210

89. Kannourakis G, Johnson GR, Begley CG, Werkmeister JA, Burns GF. Enhancement of in vitro beta-thalassemic and normal hematopoiesis by a noncytotoxic monoclonal antibody, 9.1C3: evidence for negative regulation of hematopoiesis by monocytes and natural killer cells. Blood. (1988) 72:1124-33. doi: 10.1182/blood.v72.4.1124.1124

90. Meyaard L, Adema GJ, Chang C, Woollatt E, Sutherland GR, Lanier LL, et al. LAIR-1, a novel inhibitory receptor expressed on human mononuclear leukocytes. Immunity. (1997) 7:283-90. doi: 10.1016/s1074-7613(00)80530-0

91. Meyaard L. The inhibitory collagen receptor LAIR-1 (CD305). J Leukoc Biol. (2008) 83:799-803. doi: 10.1189/jlb.0907609

92. Poggi A, Tomasello E, Ferrero E, Zocchi MR, Moretta L. p40/LAIR-1 regulates the differentiation of peripheral blood precursors to dendritic cells induced by granulocyte-monocyte colony-stimulating factor. Eur I Immunol. (1998) 28:2086-91. doi: 10.1002/(SICI)1521-4141(199807)28:073.0. $\mathrm{CO} ; 2-\mathrm{T}$

93. Verbrugge A, de Ruiter T, Geest C, Coffer PJ, Meyaard L. Differential expression of leukocyte-associated Ig-like receptor-1 during neutrophil differentiation and activation. J Leukoc Biol. (2006) 79:828-36. doi: 10.1189/ jlb.0705370

94. Florian S, Sonneck K, Czerny M, Hennersdorf F, Hauswirth AW, Buhring HJ, et al. Detection of novel leukocyte differentiation antigens on basophils and mast cells by HLDA8 antibodies. Allergy. (2006) 61:1054-62. doi: 10.1111/j. 1398-9995.2006.01171.x
95. Maasho K, Masilamani M, Valas R, Basu S, Coligan JE, Borrego F. The inhibitory leukocyte-associated Ig-like receptor-1 (LAIR-1) is expressed at high levels by human naive T cells and inhibits TCR mediated activation. Mol Immunol. (2005) 42:1521-30. doi: 10.1016/j.molimm.2005.01.004

96. Van Der Vuurst de Vries AR, Clevers H, Logtenberg T, Meyaard L. Leukocyte-associated immunoglobulin-like receptor-1 (LAIR-1) is differentially expressed during human $B$ cell differentiation and inhibits B cell receptor-mediated signaling. Eur J Immunol. (1999) 29:3160-7. doi: 10.1002/(SICI)1521-4141(199910)29:103.0.CO;2-S

97. Ouyang W, Ma D, Lin D, Sun Y, Liu X, Li Q, et al. 9.1C3 is identical to LAIR-1, which is expressed on hematopoietic progenitors. Biochem Biophys Res Commun. (2003) 310:1236-40. doi: 10.1016/j.bbrc.2003.09.152

98. Jansen CA, Cruijsen CW, de Ruiter T, Nanlohy N, Willems N, JanssensKorpela PL, et al. Regulated expression of the inhibitory receptor LAIR-1 on human peripheral $\mathrm{T}$ cells during $\mathrm{T}$ cell activation and differentiation. Eur $J$ Immunol. (2007) 37:914-24. doi: 10.1002/eji.200636678

99. Lebbink RJ, de Ruiter T, Adelmeijer J, Brenkman AB, van Helvoort JM, Koch $\mathrm{M}$, et al. Collagens are functional, high affinity ligands for the inhibitory immune receptor LAIR-1. J Exp Med. (2006) 203:1419-25. doi: 10.1084/jem. 20052554

100. Son M, Santiago-Schwarz F, Al-Abed Y, Diamond B. Clq limits dendritic cell differentiation and activation by engaging LAIR-1. Proc Natl Acad Sci USA. (2012) 109:E3160-7. doi: 10.1073/pnas.1212753109

101. Olde Nordkamp MJ, van Eijk M, Urbanus RT, Bont L, Haagsman HP, Meyaard L. Leukocyte-associated Ig-like receptor-1 is a novel inhibitory receptor for surfactant protein D. J Leukoc Biol. (2014) 96:105-11. doi: 10. 1189/jlb.3AB0213-092RR

102. Meyaard L, Hurenkamp J, Clevers H, Lanier LL, Phillips JH. Leukocyteassociated Ig-like receptor-1 functions as an inhibitory receptor on cytotoxic T cells. J Immunol. (1999) 162:5800-4.

103. Verbrugge A, Rijkers ES, de Ruiter T, Meyaard L. Leukocyte-associated Ig-like receptor-1 has $\mathrm{SH} 2$ domain-containing phosphatase-independent function and recruits C-terminal Src kinase. Eur J Immunol. (2006) 36:190-8. doi: $10.1002 /$ eji.200535226

104. Ouyang W, Xue J, Liu J, Jia W, Li Z, Xie X, et al. Establishment of an ELISA system for determining soluble LAIR-1 levels in sera of patients with HFRS and kidney transplant. J Immunol Methods. (2004) 292:109-17. doi: 10.1016/j.jim.2004.06.005

105. Lebbink RJ, van den Berg MC, de Ruiter T, Raynal N, van Roon JA, Lenting PJ, et al. The soluble leukocyte-associated Ig-like receptor (LAIR)-2 antagonizes the collagen/LAIR-1 inhibitory immune interaction. J Immunol. (2008) 180:1662-9. doi: 10.4049/jimmunol.180.3.1662

106. Bachelet I, Munitz A, Levi-Schaffer F. Abrogation of allergic reactions by a bispecific antibody fragment linking IgE to CD300a. J Allergy Clin Immunol. (2006) 117:1314-20. doi: 10.1016/j.jaci.2006.04.031

107. Borrego F. The CD300 molecules: an emerging family of regulators of the immune system. Blood. (2013) 121:1951-60. doi: 10.1182/blood-2012-09435057

108. Clark GJ, Ju X, Tate C, Hart DN. The CD300 family of molecules are evolutionarily significant regulators of leukocyte functions. Trends Immunol. (2009) 30:209-17. doi: 10.1016/j.it.2009.02.003

109. Martinez-Barriocanal A, Arcas-Garcia A, Magallon-Lorenz M, Ejarque-Ortiz A, Negro-Demontel ML, Comas-Casellas E, et al. Effect of specific mutations in Cd300 complexes formation; potential implication of Cd300f in multiple sclerosis. Sci Rep. (2017) 7:13544. doi: 10.1038/s41598-017-12881-8

110. Murakami Y, Tian L, Voss OH, Margulies DH, Krzewski K, Coligan JE. $\mathrm{CD} 300 \mathrm{~b}$ regulates the phagocytosis of apoptotic cells via phosphatidylserine recognition. Cell Death Differ. (2014) 21:1746-57. doi: 10.1038/cdd.2014.86

111. Vitalle J, Terren I, Orrantia A, Zenarruzabeitia O, Borrego F. CD300 receptor family in viral infections. Eur J Immunol. (2019) 49:364-74. doi: 10.1002/eji. 201847951

112. Voss OH, Murakami Y, Pena MY, Lee HN, Tian L, Margulies DH, et al. Lipopolysaccharide-induced $\mathrm{CD} 300 \mathrm{~b}$ receptor binding to toll-like receptor 4 alters signaling to drive cytokine responses that enhance septic shock. Immunity. (2016) 44:1365-78. doi: 10.1016/j.immuni.2016.05.005

113. Alvarez Y, Tang X, Coligan JE, Borrego F. The CD300a (IRp60) inhibitory receptor is rapidly up-regulated on human neutrophils in response to inflammatory stimuli and modulates CD32a (FcgammaRIIa) mediated 
signaling. Mol Immunol. (2008) 45:253-8. doi: 10.1016/j.molimm.2007. 05.006

114. Bachelet I, Munitz A, Moretta A, Moretta L, Levi-Schaffer F. The inhibitory receptor IRp60 (CD300a) is expressed and functional on human mast cells. $J$ Immunol. (2005) 175:7989-95. doi: 10.4049/jimmunol.175.12.7989

115. Silva R, Moir S, Kardava L, Debell K, Simhadri VR, Ferrando-Martinez $\mathrm{S}$, et al. CD300a is expressed on human B cells, modulates BCR-mediated signaling, and its expression is down-regulated in HIV infection. Blood. (2011) 117:5870-80. doi: 10.1182/blood-2010-09-310318

116. Lopez-Sejas N, Campos C, Hassouneh F, Sanchez-Correa B, Tarazona R, Pera A, et al. Effect of CMV and Aging on the Differential Expression of CD300a, CD161, T-bet, and Eomes on NK Cell Subsets. Front Immunol. (2016) 7:476.

117. Lankry D, Simic H, Klieger Y, Levi-Schaffer F, Jonjic S, Mandelboim O. Expression and function of CD300 in NK cells. J Immunol. (2010) 185:287786. doi: 10.4049/jimmunol.0903347

118. Birge RB, Boeltz S, Kumar S, Carlson J, Wanderley J, Calianese D, et al. Phosphatidylserine is a global immunosuppressive signal in efferocytosis, infectious disease, and cancer. Cell Death Differ. (2016) 23:962-78. doi: 10. 1038/cdd.2016.11

119. Lankry D, Rovis TL, Jonjic S, Mandelboim O. The interaction between CD300a and phosphatidylserine inhibits tumor cell killing by NK cells. Eur J Immunol. (2013) 43:2151-61. doi: 10.1002/eji.201 343433

120. Simhadri VR, Andersen JF, Calvo E, Choi SC, Coligan JE, Borrego F. Human CD300a binds to phosphatidylethanolamine and phosphatidylserine, and modulates the phagocytosis of dead cells. Blood. (2012) 119:2799-809. doi: 10.1182/blood-2011-08-372425

121. Zenarruzabeitia O, Vitalle J, Eguizabal C, Simhadri VR, Borrego F. The Biology and disease relevance of CD300a, an inhibitory receptor for phosphatidylserine and phosphatidylethanolamine. J Immunol. (2015) 194:5053-60. doi: 10.4049/jimmunol.1500304
122. Martinez-Martin N, Ramani SR, Hackney JA, Tom I, Wranik BJ, Chan M, et al. The extracellular interactome of the human adenovirus family reveals diverse strategies for immunomodulation. Nat Commun. (2016) 7:11473. doi: 10.1038/ncomms11473

123. Sun X, Huang S, Wang X, Zhang X, Wang X. CD300A promotes tumor progression by PECAM1, ADCY7 and AKT pathway in acute myeloid leukemia. Oncotarget. (2018) 9:27574-84. doi: 10.18632/oncotarget. 24164

124. Jiang L, Xu Y, Zeng X, Fang J, Morse HC III, Zhou JX. Suppression of CD300A inhibits the growth of diffuse large B-cell lymphoma. Oncotarget. (2015) 6:31191-202. doi: 10.18632/oncotarget.5152

125. Raggi F, Blengio F, Eva A, Pende D, Varesio L, Bosco MC. Identification of CD300a as a new hypoxia-inducible gene and a regulator of CCL20 and VEGF production by human monocytes and macrophages. Innate Immun. (2014) 20:721-34. doi: 10.1177/1753425913507095

126. Schumann T, Adhikary T, Wortmann A, Finkernagel F, Lieber S, Schnitzer E, et al. Deregulation of PPARbeta/delta target genes in tumor-associated macrophages by fatty acid ligands in the ovarian cancer microenvironment. Oncotarget. (2015) 6:13416-33. doi: 10.18632/oncotarget.3826

Conflict of Interest: The authors declare that the research was conducted in the absence of any commercial or financial relationships that could be construed as a potential conflict of interest.

Copyright (c) 2020 Sivori, Della Chiesa, Carlomagno, Quatrini, Munari, Vacca, Tumino, Mariotti, Mingari, Pende and Moretta. This is an open-access article distributed under the terms of the Creative Commons Attribution License (CC BY). The use, distribution or reproduction in other forums is permitted, provided the original author(s) and the copyright owner(s) are credited and that the original publication in this journal is cited, in accordance with accepted academic practice. No use, distribution or reproduction is permitted which does not comply with these terms. 